\title{
Special Problems in Reclassification and Recataloging
}

Mr. Tauber is chief, Catalog Department, University of Chicago Libraries.

TN AN EARLIER PAPER, ${ }^{1}$ it was indicated 1 that a number of complex problems are created by introducing projects of reclassification and recataloging into academic $^{2}$ libraries. Consideration will be given here to a group of special problems which may be peculiar to individual libraries, or to small groups of libraries, but are probably of interest to most administrators and technicians. These problems concern ( $\mathrm{I}$ ) classification of special types of materials, (2) open-shelf collections, (3) letter classifications, (4) arrears in cataloged and classified materials, (5) experimentation in filing, (6) uses of films, (7) discarding and storage, and (8) union catalogs. These matters will be treated in relation to practices in a group of sixty college and university libraries which have either completed reclassification or are still reclassifying by the Library of Congress system and in six other libraries which have always used the Library of Congress system. A few points made are based upon the possible future development of libraries rather than upon prevalent present practice. They are noted, however,

- Tauber, Maurice F. "Reclassification and $\mathrm{Re}$ cataloging of Materials in College and University Libraries." In Randall, William M., ed. The Acquisition and Cataloging of Books. University of Chi-

cago Press, I940, p. I87-219. lege and university." for they may aid in throwing light upon questions which are frequently omitted in discussions of the problem of reorganizing the technical processes.

\section{Classification of Special Types of Materials}

Institutional differences among libraries will necessarily result in variations in practice in regard to the placement of certain types of materials during reclassification. For example, what should be done about the placement of subject bibliographies? Of biographies? Of fiction? Of textbooks? Of juvenile collections? Of periodicals? It may be observed that libraries employing the Library of Congress classification are not faced with the same problem in arranging these materials as they are in the placement of classes of materials for which no Library of Congress schedules $^{3}$ exist or in situations wherein inadequacies in the schedules are present. ${ }^{4}$ The question concerns the variations and the possible reasons for them. The discussion of the practices relating to the handling of these special types of materials should clarify rather than settle points of controversy and should enable one to proceed along whatever lines the best interests of a particular library seem to indicate.

\footnotetext{
${ }^{3}$ E.g., Law.

4 Tauber, $o p$. cit., p. 21 I-12.
} 


\section{Bibliographies}

The whole problem of whether to place bibliographies with the subject or in the special class $Z$ (Bibliography) is presented to the librarian who is reclassifying by the Library of Congress system. One may not say categorically which is the better procedure. Yet, on the basis of the practices of the libraries included in the study, the major choice ( 82 per cent) has been to follow the Library of Congress assignments and build up a special collection of bibliographies in the $Z$ ( IOOI-9000) class. Another method which is claimed by its adherents to result in effective grouping is to assign the bibliographical item its subject notation and then preface the number by the letter $Z$, that is ZQE $75 . A_{22}$ for Nickles' Bibliography of North American Geology. It should be noted that the Library of Congress itself frequently places its second copy with the subject rather than in $Z$.

\section{Biographies}

The placement of biographies presents a problem similar to that raised by bibliographical materials. Generally, libraries have followed the Library of Congress practice of placing biographies with the subject. For those titles which are difficult to place with a specific subject, CT (Biography) is used. At least six libraries, however, use CT for all their biographical works. The experience of librarians has indicated that most users of academic libraries are more satisfied to find biographical material with the subjects rather than in a single alphabetical order by the names of the biographees.

\section{Fiction}

In larger libraries fiction has been placed with the literature of the country of the author. The class $P Z_{3}$, used by the $\mathrm{Li}$ brary of Congress for most of its fiction, has thus been eliminated in twenty-eight libraries. Apparently in academic libraries it has been found more useful to the patrons to arrange fiction according to the literature of the country rather than in a single alphabetical order. There is more divergence of opinion in regard to the handling of fiction than there is in the cases of bibliography and biography. Eighteen libraries place all fiction in $\mathrm{PZ}_{3}$.

\section{Textbooks}

The arrangement of textbooks has presented special problems to those institutions which maintain teacher-training schools or divisions. The large collections of elementary, secondary, and junior college texts, sometimes reaching five thousand or more volumes, apparently do not best serve their purposes for comparison and consultation by teachers and prospective teachers when they are dispersed in a general collection of two or three hundred thousand volumes. For this reason there has been a tendency on the part of libraries with teacher-training divisions to segregate textbook materials in special collections. But the large majority of libraries (7o per cent) have treated textbooks which are below the level of higher education just as they have other materials, that is, arranged them in their respective places according to Library of Congress practice. If we add the I 5 per cent of libraries which follow Library of Congress practice, which generally means placement with subject, it may be said that approximately 85 per cent of the libraries class textbooks with the subject. An interesting special classification has been 
devised in one library by using the Library of Congress class number assignments and prefixing LT to the numbers to throw them into a distinct grouping. The results seem uniformly better than in the four institutions which have devised special classifications based upon broad Dewey numbers prefixed by the letters LT.

\section{Juvenile Works}

The presence of juvenile collections, which are used in connection with teachertraining schools by the pupils themselves or by students preparing to be teachers, presents a problem similar to that of textbooks. While 2 I per cent of the libraries (out of fifty-eight libraries) place such materials with the subject, the more prevalent practice is to segregate such materials in the Library of Congress $\mathrm{PZ}_{5}$ class. The latter grouping is probably more effective for the academic library. The placing of The Little Farmer on the shelf beside a scientific treatise on agriculture hardly seems a satisfactory procedure in an academic library so far as probable use is concerned.

\section{Periodicals}

Periodicals generally have been reclassified along with books. In several libraries the classification of periodicals has been for shelflist purpose only, that is, the periodicals are classified and then arranged alphabetically by title on the shelves. Evidence based on observation alone indicates that the approach of most users to periodicals generally has not been on the basis of subject groupings of the titles but by specific articles. Subject groupings of periodicals, however, probably aid the user who is working on a special topic by bringing together a similar group of journals. Two libraries decided to reclassify the periodicals after the process of reclassification had been in progress for several years because experience had demonstrated that the readers in the stacks found an alphabetical arrangement difficult to use when periodical titles changed or merged. Stack attendants were presented with a similar difficulty in locating and shelving materials. Thus, the reclassification of periodicals along with books may be undertaken primarily for purposes of administrative efficiency.

\section{Other Materials}

Such materials as government documents and dissertations of other institutions present problems which need consideration during reclassification. For example, the evidence from a few libraries indicates that there is a tendency to follow Library of Congress assignments in both these classes of materials. In a few instances librarians have arranged documents chronologically or according to the classification of the Documents Office. Theses of other institutions are sometimes arranged chronologically under the names of the issuing institutions rather than under the subject.

\section{Summary Note}

The methods of treating special types of materials during reclassification depend upon the purposes of the library and the characteristics of the users. Majority practices are not always the best criteria. However, it should be emphasized that unless local conditions are likely to be permanent, the adoption of ill-advised arrangements may prove expensive variations without proportionate returns in user satisfaction. 


\section{Cutter and Letter Classifications}

In two libraries modifications of the Cutter classification were employed in the arrangement of books. The presence of a letter notation such as that which characterizes the Cutter system and two of the local classifications which were used may raise annoying administrative problems. In order to preserve system in the stacks for faculty members and students using volumes at the shelves and to remove difficulties from the tasks of the loan attendants or stack assistants in securing books with dispatch, a decision should be made regarding the method of distinguishing between the notation of the Library of Congress classification and that of the system being discarded. If libraries had used a pure Cutter notation, which does not include the use of digits in addition to the letters, the problem would not be pressing. However, all the libraries using either the Cutter or local letter systems had modified the arrangements to the extent of including digits as part of the call numbers. Three procedures for reducing confusion apparently have been followed: (I) To segregate on different tiers or in sections of the stack the materials classified by Cutter or letter systems from those reclassified by the Library of Congress system, (2) To remark the reclassified volumes in some distinctive way, as, for example, to shift the position of the marking or the labels, and (3) To place a temporary colored label, dot, or mark on those volumes which have been reclassified until the whole collection has been rearranged. The presence of a letter classification is a factor, although a minor one, in raising the cost of reclassification. Shifting in the stacks is usually more frequent than otherwise, and the extra task of differentiating between unreclassified and reclassified materials is introduced.

\section{Open-Shelf Libraries}

The presence of open-shelf libraries or collections creates problems for both the library staff and the users. The librarian is forced to organize the routines of reclassification so that the personnel of the catalog department will have no difficulty in working with the collection and so that the users will not be unreasonably limited in their access to materials. In most of the libraries having open-shelf collections, the procedure has been either to remove to the catalog department certain sections of a class, as, for example, all the books in the 5 IO's, while they are being processed. In other cases, certain areas have been blocked off during the reclassification process and the mechanical work done on the spot. By the latter method direct access is prohibited, but it is possible to supply materials to users without delay. The arrangement of the building is a determinant of the best procedure in regard to open-shelf collections, and it is not possible, therefore, to suggest what a certain library should do unless such factors as location of the collection, distance to the workroom, and the nature of use are considered. It may be generally stated, however, that any procedure followed should be prompted by the policy of giving complete and immediate service to the users. By a system of records in both the circulation department and the catalog department, any book which is being worked upon should be readily located. Among the faculty complaints regarding reclassification, the inability to secure books which were in process of being changed has been emphasized. 


\section{Arrears in Classified and Cataloged Materials}

With the introduction of reclassification and recataloging into a library, it is apparent that if the annual book acquisitions remain constant or increase and the number of individuals engaged in the technical processes remains constant, additional work would normally slow up the preparational operations on new accessions. In many of the libraries studied increases in acquisitions without a proportionate increase in staff to handle reclassification occurred. It may be observed that reclassification most often takes place in a library in which the book collections are rapidly increasing rather than in a library that has reached a stationary stage in development.

It is difficult to say whether or not reclassification is entirely responsible for arrearage in cataloged and classified materials but there seems to be little doubt that it is a contributing factor. In eighteen of the libraries it was possible to observe some relationship between reclassification and arrears. In seven libraries that could provide approximate figures of arrears attributable to reclassification, the number of volumes ranged from three hundred to twenty thousand. Five libraries reported ten thousand or more volumes in arrears.

The question of arrearage as a result of reclassification or of other reasons poses a real problem for librarians and suggests a worth-while topic for further investigation. This refers to the actual use made of materials in libraries of institutions of higher education. Is it more important to make available materials of recent imprint than it is to expend a large portion of the time of the technical personnel in reclassifying and recataloging older materials which may be rarely used by a research student? A study of the use of library materials is fundamental to reach a conclusion on the question of whether or not reclassification is desirable in a particular library. In this connection, an experimental library arranged by a period classification such as suggested by Lund and Taube $^{5}$ should reveal some interesting facts regarding actual use of materials.

\section{Experimentation in Filing}

Among the important practical problems of the user of card catalogs is the method of arranging the cards in the trays. Skill in filing was once considered among the peculiar acquirements of the librarian and his ability to file was regarded as an esoteric talent. But more important than the ability of the librarian to file cards is the success of the user in locating entries after the cards have been arranged in their alphabets and subalphabets. In the preliminary plans for a reclassification project the librarian should carefully analyze the filing situation. What difficulties existed in the filing system up to the time of reclassification and recataloging? A survey of the users and staff members on the question of the ease or difficulty in locating materials through the catalog should provide the librarian with more than a subjective basis on which to introduce a new filing code. Among the sixty libraries reclassifying thirty-eight retained their old filing systems. Ten of the libraries which changed adopted the Pittsburgh rules; three, the Cleveland code; two, the Cincinnati rules; two, the University of Chicago rules, which embodies

\footnotetext{
5 Lund, John J., and Taube, Mortimer. "A Non5 Lund, John J., and Taube, Mortimer. "A NonExpansive Classification System: An Introduction to
Period Classification." Library Quarterly $7: 373-94$, July 1937 .
} 
simplified alphabetizing; and one, modified Library of Congress rules. Four libraries use a combination of several codes. There is reason to believe that if the Library of Congress had published its rules more libraries would have used them.

In connection with the rehandling of all cards during complete reclassification and recataloging, there is also the possibility of introducing experiments in filing systems. The divided catalog, for example, is assumed to meet the reader's approach to the catalog. In all libraries included in the study not one librarian ventured to set up the divided catalog at the start of reclassification. Recently in one of the libraries the catalog has been divided. It should be pointed out that the adoption of the split catalog during reclassification will involve considerable effort on the part of the users. The old catalog and the two parts of the new catalog may possibly present a psychological hazard. Also, the split catalog requires a total rearrangement of the tray space and probably the purchase of new equipment.

\section{Uses of Film}

Implications are raised for using films during projects of reclassification. The possibilities in this connection relate to (I) storage and (2) union catalogs.

The storage of little-used materials apart from the central book stock may be accompanied by a similar storage of cata$\log$ cards for the materials. It has been suggested, for example, that the card catalogs be reduced in size by the elimination of subject cards for materials that are seldom used. While selective cataloging may permanently eliminate cards from the catalog, the use of microfilm techniques may make it possible to remove inactive cards from the file and still keep them for reference purposes. It should be apparent that any librarian having intentions of storing materials during reclassification should consider the possibilities of microfilming the card records for the materials.

Films may also be used as aids in compiling union catalogs. Since reclassification and recataloging are often utilized as an opportunity to prepare a union catalog of all the libraries on a campus or of all libraries which are part of an academic institution, films furnish two distinct uses. In the first place, copies of all catalogs of departmental libraries may be made and used in the catalog department during the reclassification process. This is particularly true if the departmental libraries had been independent and complete records were not held by the central library. In the second place, films may be used for a deliberate compilation of a union catalog of all materials in the various units of the institution. This use of film applies only in case the library has not taken advantage of the opportunity of duplicating cards for a union catalog during the initial stages of reclassification and recataloging.

\section{Discarding and Storage}

Some librarians have considered the problems of discarding and storage of various types of materials as part of reclassification and recataloging. Despite the recent revival of the proposal that college libraries, and to a lesser extent university libraries, weed their collections, most librarians who have undertaken reclassification and recataloging recently have not seen fit to use these processes as an opportunity to reconsider the right of an item to occupy space on the shelf. 
It is perhaps thoughtless on the part of the librarian not to use reclassification and recataloging as a means to weed the duplicate collection of the library. For example, the reclassification of twenty-six copies of a botany textbook or thirty copies of an old education textbook, even though the library has copies of new editions of both titles, is without question a waste of time and results in an inefficient use of shelf space.

The possible effects of storage and reservoir libraries upon the processes of reclassification and recataloging should be noted. If the growth of academic libraries continues at the present pace, the next half century should witness increased library building or, as it is now being studied seriously, the construction of storage libraries. The elimination of little-used titles and duplicates from the stacks of the active materials, therefore, should have definite meaning in a program of reclassification and recataloging. The need to assimilate materials from a number of libraries will require some reorganization of the cataloging and classifying practices of the contributing units. Since this is a problematical matter, no definite statement of what should be done will be made at this time. But no study of storage plans which involves a group of libraries should neglect to review the possible effects the arrangements might have on the technical processes in the individual libraries.

\section{Union Catalogs}

The rise of union catalogs in the United States is a comparatively recent movement. Twelve of the college and university libraries included in the present study have been contributing members to union catalogs. In most cases, however, the union catalogs started after reclassification was under way or near completion in the libraries. This particular section of this paper is concerned with the possibilities of using union catalog services and methods during a reclassification and recataloging project. The relations of reclassification and recataloging to union catalogs appear in three ways: (I) The use of union catalogs themselves for purposes of cataloging, (2) The use of film during the general process of reclassification for establishing a union catalog of materials on the campus, and (3) The improvement of cataloging generally in an area through the establishment of uniformity in entries.

\section{Union Catalogs and Recataloging}

In several of the college and university libraries which still maintain in their catalogs thousands of handwritten cards of doubtful entry, the utilization of the union catalog may be highly desirable. While no library included in the group under investigation has actually been engaged in a project of this type, a large private library, the Library Company of Philadelphia, has taken advantage of this use of the union catalog. This project involves the use of labor furnished by the W.P.A. to copy all the cards in the Philadelphia Union Catalogue which have the name of the Library Company of Philadelphia stamped on them. ${ }^{6}$ As about 70 per cent of these cards have been duplicated by libraries which have been better cataloged than the Library Company of Philadelphia and many more could be identified through bibliographical sources,

${ }^{6}$ Started in 1939. See Berthold, A. B. "Union Catalogues and Documentation." In Federation Internationale de Documentation. XVieme Conférence Internationale, Zurich, IO-I3, Aout, 1039 . P. $\mathrm{C}_{\mathrm{I}} \cdot \mathrm{C}_{5}$. 
a substantially good catalog was expected to result. It is admitted that such a procedure has certain drawbacks and the new catalog would not be perfect but it represents an experiment that merits the attention of librarians. Untrained labor, for example, may be used in such a project, and librarians who do not have adequate budgets for a complete recataloging may well consider its potentialities. ${ }^{7}$

\section{University or College Union Catalog}

In eight libraries the reclassification and recataloging project was grasped as an opportunity to prepare a central or union catalog of materials in all libraries of the institutions. It has been generally accepted that to maintain effective service without considerable duplication the central library of an academic institution needs a record of the books and other materials in all libraries of the college or university. Under ordinary conditions it may be extremely difficult and expensive for a library to attempt to compile a central catalog of all holdings. Commenced at the beginning of a project of reorganization, however, the making of a central catalog may be only a mechanical routine. There seems to be no reason why the librarian should not be able to determine what type of catalogs and shelflists will be needed in the future development of the library and start them at the beginning of the project. Lack of foresight on the part of some librarians in this respect has been notable.

"Ibid., p. $\mathrm{C}_{3}$. Berthold writes: "We have no hesitation in saying that it (the procedure) could be applied with more than a fair degree of success to a large number of libraries with antiquated catalogues.'

\section{Improvement of Cataloging in an Area}

Through their activities in bringing uniformity in the numerous entries in their own files, officials of union catalogs are able to observe the many variations which occur in the entries of contributing libraries. They are thus able to establish what may be termed the most logical entries, and the contributing libraries are in a position to utilize these data for their own files. The maintenance of an information service at the union catalogs may well be taken advantage of by college and university librarians who are in the throes of reclassification and recataloging. In essence it is a form of cooperative cataloging. The union catalog officials may be active agents in inducing librarians to conform in their entries to those adopted by the union catalog, or the librarians themselves may try to gather information relevant to difficult or obscure entries. Useful variations within a particular library, of course, should be adopted.

\section{Summary}

On the basis of the experience of the libraries investigated, therefore, three points may be emphasized: (I) There is a definite need for advance planning before a project of reorganization is started. (2) There is need for thoughtful consideration by librarians of the practice of introducing local variations which are of doubtful superiority to the practices of the Library of Congress, and (3) There should be more attention paid to the possibilities of giving a higher plane of service to users through economies within the library or through cooperative enterprises. 